\title{
Co-Creating Authentic Sacred Therapeutic Space: A Spiritually Sensitive Framework for Counselling Children
}

\author{
Heather M. Boynton * and Christie Mellan
}

check for updates

Citation: Boynton, Heather M., and Christie Mellan. 2021. Co-Creating Authentic Sacred Therapeutic Space: A Spiritually Sensitive Framework for Counselling Children. Religions 12: 524. https://doi.org/10.3390/ rel12070524

Academic Editor: Kelvin Mutter

Received: 28 May 2021

Accepted: 29 June 2021

Published: 12 July 2021

Publisher's Note: MDPI stays neutral with regard to jurisdictional claims in published maps and institutional affiliations.

Copyright: (c) 2021 by the authors. Licensee MDPI, Basel, Switzerland. This article is an open access article distributed under the terms and conditions of the Creative Commons Attribution (CC BY) license (https:// creativecommons.org/licenses/by/ $4.0 /)$.
Faculty of Social Work, University of Calgary, Edmonton, AB T5J 4P6, Canada; cjmellan@ucalgary.ca

* Correspondence: hmboynto@ucalgary.ca

\begin{abstract}
Social work values client-centered holistic approaches of care, yet there is a lack of approaches addressing spirituality in counselling with children. Children's spirituality and conceptualization have been disenfranchised. Children's spiritual experiences, ways of knowing and perceptions are important to attend to when supporting them through an impactful life event such as trauma, grief, or loss (TGL). Parents may not fully understand or have the capacity to attend to their child's spirituality. Counsellors appear to lack knowledge and training to attend to the spiritual needs and capacities of children. This article offers some research findings of children's spirituality deemed to be vital for healing from TGL and counselling. It provides an understanding of some of the constructs and isolating processes described by children, parents and counsellors related to children's spirituality in TGL. It also will present a spiritually sensitive framework specifically attuned to the spiritual dimension and creating spaces of safety and hope when working with children. The implications of not addressing the critical spiritual dimensions in practice for children are discussed, and recommendations for continued research and training for further theoretical development and future social work practice are offered.
\end{abstract}

Keywords: children's spirituality; counselling; social work; trauma; grief and loss

\section{Introduction}

Typically, counsellors working with children who have experienced trauma, grief, and loss (TGL) will focus on the cognitive, emotional, and physical symptoms and aspects; however, the spiritual dimension, which can be central to the experience, is often overlooked and disenfranchised. This dismissal leads to a lack of spiritually sensitive frameworks and treatment strategies that honour and support children's spirituality in counselling. Consequently, neglect of children's spirituality can result in missed opportunities for counsellors to draw upon spiritual resources and supports and identify spiritual needs and the development of spiritually integrative approaches to help children through adversity, such as TGL. We contend that the spiritual dimension is essential when treating TGL and in facilitating posttraumatic growth (PTG) for children. Counsellors focused on understanding the spiritual aspects of children, and opening space to attend to any important spiritual narratives, strengths, and practices, as well as distress, struggles, and concerns, will offer greater support for children, especially when experiencing TGL.

We argue that it is critical for counsellors to create space for the sacred and be open to the spiritual dimension if they are to apply a holistic counselling approach, whereby children fully engage and typically prefer. We provide research and literature, as well as children's own conceptualizations of spirituality, which will inform practitioners on the spiritual dimension for the child. We also share how children engage in and experience spirituality, connect with their various spiritual relationships, and how they integrate diverse aspects into a robust spiritual foundation.

A scan of the literature demonstrates that much of the research conducted in children's spirituality is grounded in child development and Early Childhood Education (Bosacki and Ota 2000; Fowler 1981; Hay and Nye 2006; Hyde 2008; Ratcliff 2008; Roehlkepartain et al. 
2006). Many proponents of holistic education have argued for the inclusion of the spiritual dimension in educational frameworks (Miller 2007; McLaughlin 1996). Moreover, the intersection of TGL and its impacts and effects on development and growth are incomplete as they omit children's spirituality. Currently, social workers and counsellors must rely on the deficient research and literature across different professions due to the absence of specific frameworks related to children's spirituality. Social work practitioners are then tasked with translating education or other professions' understandings of spirituality into an ethical counselling practice with children. This article aims to address these needs and to contribute to the dialogue, research, and literature regarding the spiritual needs and strengths of children involved in counselling for TGL. It also offers a spiritually sensitive framework for counsellors. Lastly, we strongly advocate, along with previous researchers, for continued research to support further theoretical development, and education and training for social workers who will inevitably encounter children's spirituality in counselling practice (Kvarfordt and Sheridan 2007; Kvarfordt and Herba 2018; Moore et al. 2012). This article draws on the findings of Boynton's first PhD research work that employed a constructivist grounded theory approach and was conducted in Northwestern Ontario, Canada, in which she interviewed six children 8-12 years of age experiencing TGL, five parents, and seven clinicians in an outpatient counselling centre. Ethical approval for this study was obtained at the University of Calgary and at the counselling centre where the research was conducted. The research question was "What are the processes, experiences, and understandings of children's spirituality for children, their parents, and clinicians involved in trauma, grief, and loss outpatient counselling?"

The core category of this research was Navigating in Seclusion, which described an isolating experience of children's spirituality and two dialectical meaning constructions of spirituality that deemed it to be weird and taboo and normal and important. The results pertaining to the category of weird and taboo and its resultant processes and struggles regarding spirituality are discussed in another manuscript (Boynton 2021), whereas this paper will shed more light on some of the normal and important aspects of children's spirituality and a framework for counselling. We offer this knowledge with the aim of mitigating some of the social constructs and processes found to impede crucial conversations and openness regarding children's spirituality. We want to begin to provide a map to for navigating conversations about spirituality with children and parents. As such, we will raise awareness on the importance of situating the child's spiritual worldview at the centre of the counselling process and highlight the implications of not addressing the spiritual dimension in practice with children.

\section{Creating Space for the Sacred in Counselling Children}

Creating space for the sacred in counselling begins with a spiritually sensitive framework for working with children experiencing TGL. Our framework is a first attempt at providing a roadmap for counsellors. It is grounded in research, theory, and literature supporting children's conceptualizations, experiences, and desires related to spirituality and counselling for TGL. The framework values the child's perspective in creating space for open expression of spirituality, while bearing witness to the impacts of TGL, and offering safety, healing, and hope. The framework embraces openness, inquiry, honouring, and acceptance as tools of safety and hope. These tools help facilitate spiritual dialogue, support the child, and may foster PTG. We have used verbs as we believe this should be an ongoing, dynamic, and spiritually co-creative process for the child and the clinician. The first four components focus on how counsellors can understand a holistic approach that includes spirituality. The final four components focus on how counsellors can integrate children's spirituality into practice when supporting children through TGL. The framework entails:

i. Conceptualizing spirituality and its diversity, complexity, and multidimensionality, and its intersection with and difference from religion and religiosity.

ii. Accepting children as spiritual beings through adopting a holistic lens and attuning to relational consciousness. 
iii. Opening one's heart for sacred relationships; developing skills for genuine connection and deep empathy for engaging children.

iv. Recognizing the role of spirituality and supporting children in TGL, meaning making, development of worldview, and identity formation or revision.

v. Creating a safe space for spirituality to enter through openness, exploration, inquiry, discussion, and validation.

vi. Honouring spiritual emergence and sacred creative expression.

vii. Facilitating spiritual coping and growth.

viii. Expecting the unexpected.

\section{Conceptualizing Spirituality and Its Diversity}

Spirituality is multidimensional in that it is intrapersonal, interpersonal, and transpersonal (Swinton 2001), and it is a complex construct with various aspects and dimensions. It is influenced by contextual factors, space, time, and place. There are many definitions in the literature which speak to the expansiveness of spirituality and its unique nature for each individual. Within the social work literature, Canda et al. (2020) suggested using an "open working definition" which takes "into account previous scholarly work" (p. 82). They highlighted that spirituality is viewed by many as a search for or a sense of connectedness to self, others, nature, and the earthly world, and with the universe. They further conveyed that it relates to the transcendent, and to a higher power or being, and other beings or entities beyond humans. Similar definitions are found across disciplines including education, religious education, nursing, and medicine (Burkhardt 1991; De Souza 2012; Hay and Nye 2006; Koenig 2011; Woolley et al. 2008). Spirituality involves identity and developmental concerns, and it has multiple dimensions and facets including love, gratitude, virtues of hope and forgiveness, joy, values, beliefs, and it comprises the cognitive, physical, emotional, experiential, social, environmental, existential, and supernatural dimensions (Canda et al. 2020; Roehlkepartain et al. 2006). MacDonald (2000) reviewed 20 measures of spirituality and identified its relation to various dimensions including cognition, experiential/phenomenological, existential, paranormal, and religiousness. Fisher (2009) conceptualized four relational dimensions of spirituality as the personal (with self), communal (with others), environmental (with the environment), and the transcendental (with transcendent Other).

The conceptualization of spirituality includes significant aspects of the development of identity, self-discovery, or understanding of Self (the spiritual or divine aspect of oneself) (Burkhardt and Nagai-Jacobson 2002). Many of the wisdom traditions across our planet convey that the important aspects of spirituality involve cognitions and emotions of love, hope, faith, comfort, and peace, which are associated with our inner and our outer social connections, and with transcendent experiences (Canda et al. 2020). Spirituality is experienced by individuals in different and unique ways, and it overlaps with religion and religiosity.

Often spirituality and religion are used interchangeably within the literature, which can make it confounding for researchers, scholars, and practitioners. Canda and Furman (2010) conveyed that religion included the transmission of traditions over time, as well as providing community support functions. A scan of the literature highlights some consensus of religion involving institutionalized beliefs shared by a community, dogma related to a denominational identity, and that it is a means of spiritual expression involving rituals, practices, and traditions (Canda and Furman 2010; Carroll 1998; Sheridan 2004). Wilkinson (2012) elucidated seven elements of religion, which include doctrine, mythology, religious experience, religious institution, ethical content, ritual, and sacred objects. Canda and Furman (2010) deemed that religiosity is characterized as ascribing to religion and religious practices, and it can also be a vehicle of spirituality. Religiosity and religion may be pertinent for many children and families, although for others, it may not. 


\section{Children's Conceptualizations of Spirituality}

The spiritual domain of children's lives has remained unacknowledged, dismissed, pathologized, and misunderstood, thereby limiting practitioners' capacity to fully understand the child. This neglect has resulted in children experiencing social oppression regarding their spirituality and beliefs, which ultimately leads to the repression of children's natural spirituality and exploration (Boynton 2016; Hart 2003; Hay and Nye 2006). Boynton (2016) found that preadolescent children comprehend and have the capacity to discuss spirituality. They are highly open to and can think, consider, express, and philosophize about spiritual and existential concerns at advanced levels when provided with safety and opportunity.

Although children's spirituality is somewhat similar to adult conceptualizations and definitions, children have a unique perspective and way of describing their understandings and experiences of spirituality. Sveidqvist et al. (2003) found that adolescents aged 14-18 felt their spirituality provided them with a sense of support and comfort, and it was a source of strength, energy, and inspiration. Boynton (2016) discovered these assertions in youth aged 8-12 where expression of and engagement in spiritual practices also brought joy, happiness, peace, and comfort. She found that children described relating and communicating to spiritual beings and entities such animals, trees, angels, the devil, fairies, pixies, and higher powers such as God, Gaia, and Creator. The children in her study experienced the spiritual world through their bodies, their senses, and through their minds. Children described spiritual experiences as creating a sense of butterflies in the stomach region that feels good as opposed to anxious feelings of butterflies, which is similar to the findings of Lovelock and Adams (2017) who also interviewed preadolescents. They described engaging with the spiritual world through their own spirit, their heart, through human relationships and with the natural world. They described experiences of flow as described by Csikszntmihalyi (2008) that brought them creativity, inspiration, and strength, but also seemed to be a process of channeling information from a higher source beyond themselves.

These children described spirituality as pertaining to feelings, thoughts, intuition, knowledge, relationships, and activities, which contribute to a unifying holistic spiritual experience. They articulated that spirituality is associated with many virtues in life such as love, kindness, authenticity, integrity, fairness, compassion, honesty, loyalty, appreciation, and healing. Children's spirituality involved relationships of varying kinds, communication with the natural and spiritual worlds, and various practices, rituals, and activities. The children expressed that some of their spiritual experiences were ineffable. They discussed spirituality as relating to the heart and soul. Iza (8 years old) was the first child to be interviewed and, immediately, she demonstrated she had a strong grasp of what spirituality meant to her. Her understanding of spirituality was that it had to do with love and kindness, being authentic and true to yourself, and healing and much more:

Spirituality means to me that you have to love someone in your life and be nice to them and be kind and if you're not kind then this can't happen ... my strong points are actually being nice to friends, trying to let them take their own actions and also being kind... Being you ... Yes being me is how you want to be ... Life is the four elements, Life is the talent of healing, Life is believing in yourself, Life is loving yourself, but that's not all!

Children described how an individual is actively engaged with the spiritual realm and many mentioned that one's spirituality evolves over time. Children felt that spirituality involved aspects of one's whole life such as relationships with significant others, the natural world, and the spiritual world. It also involved activities that provide and create purpose through connectedness, compassion, and meaning. Bobby Boblehead (11 years old) mentioned other aspects:

Well, family, friends. I think animals are a really important part of life, especially if you're in a city and you're all alone. It's the little things like lizards - I want to get one-it's just that you know there's another presence other than yourself. You just feel a whole lot 
better. That's what I think anyway. But I think having like kindness and honesty and loyalty and school is very important to me, and so is soccer. And like being-just being compassionate or you know, accepting and understanding of others and non-judgmental ... I think that's pretty important in life, just with life as it is instead of worrying about what else is going on ... When I'm like appreciative of family, friends, animals, nature, sports and anything like that. I find it easy to tell especially ... you can catch yourself doing it. I think that's the most fun because you don't even know until afterwards. I'm like, "Well, yeah. I was being spiritual there."

The children explained how spirituality was experienced internally through thoughts, prayers, feelings, and physical sensations. Although children expressed positive expressions of spirituality, they also felt that spirituality could be experienced through negative emotions including anger, mistrust, and despair. They depicted an intuitive or perceptive nature to spirituality which individuals experience in varying degrees. All the participants felt that spirituality was very significant, important, and critical, especially in managing TGL events.

Interestingly, spiritual expressions and beliefs are present in children, even if the family unit identifies as secular or less religious or spiritual, as Boynton (2016) has found in her personal practice and research. Comparatively, Moore et al. (2012) conducted open ended semi-structured interviews with 64 preadolescents ages 6-11 in Canada from a variety of religious affiliations, varying income brackets, with $81 \%$ speaking more than one language in their home. Although $28 \%$ of parents described their children as not religious or spiritual, there were only $5 \%$ percent of children who stated they were skeptical or did not hold religious or spiritual beliefs, and these children still shared conceptions and aspects of spirituality. They also uncovered common themes from children about spirituality, regardless of the child's religious affiliation. This further demonstrates how adults, even parents who are experts in their child's life, can be unaware of children's inner spiritual cogitations and development. Therefore, it is important that counsellors not assume that the beliefs of the parent or family are those of the child. Conceptualizing spirituality within the child's worldview considers how the child understands, explains, and experiences the multidimensionality of their lived spirituality, which may or may not intersect with religion and religiosity, or parental worldviews.

In Boynton's (2016) research, preadolescent children felt that spirituality and thoughts about spiritual matters were natural, and normal and important in their life. The parent and child participants in her study identified themselves as spiritual but not religious. Although some stated they were affiliated with religions of their upbringing, they had evolving spiritual worldviews that appeared to be complex and expansive beyond religion. All participants felt that humans develop their own unique spiritual worldview and shared the belief that individuals have a right to choose what they believe and practice regarding spirituality. Although children's spirituality is influenced by culture, family relationships, generational transmission, location and context, children develop and exert agency in creating their own spiritual foundation.

\section{Accepting Children as Spiritual Beings Through Adopting a Holistic Lens}

Creating and opening space for children's spirituality in practice begins with accepting children holistically as spiritual beings and adopting a holistic lens. Canda and Furman (2010) believe that "holistic helping is healing" and is part of a strengths-oriented practice that includes spirituality (p. 222). A social worker who has developed a spiritually sensitive practice will assess whether and how the spiritual dimension is a significant factor in the worldview and within the events of TGL for the child. Hawkins (2005) discusses various guidelines for a spiritually sensitive practice including affirming, conveying the importance of the child's worldview, and using language and images congruent with the child's worldview. These approaches work towards strengthening the therapeutic relationship with the child. She further discusses the importance of discerning the child's cognitive, moral and faith development, distinguishing between healthy and unhealthy 
practices, and knowing when to refer to clergy or the appropriate religious or spiritual leader as critical.

Consequently, one of the most crucial steps of embracing a spiritually sensitive framework is to consider what one's own spiritual beliefs, values, and worldviews are, and how this may impact a practitioner's work within the counselling realm. One can then consider the spiritual worldview and unique spiritual expressions and experiences of the children they encounter in their practice. Embracing a stance of spiritual humility when exploring the child's spiritual worldview is critical.

\section{Attuning to Relational Consciousness in Children}

Several researchers have described the spirituality of children to be innate (Coles 1990; Hart 2003; Hay and Nye 2006; Hyde 2008; Reimer and Furrow 2001). Hay and Nye (1998) coined the construct relational consciousness, which they describe as "an unusual level of consciousness or perceptiveness", where children have the capacity to express things within "a context of how the child related to things, other people, him/herself, and God" (p. 109). It appears that children demonstrate this awareness and capacity at very young ages and that humans are predisposed to recognize and understand spiritual interconnectedness (Champagne 2001; Coles 1990).

Reimer and Furrow (2001) identified an existential map, along with a socio-contextual framework, which described unique spiritual experiences not typically shared with others and could hold clues to the mental representations of spiritual knowledge for children. They surmised that some of the children's spiritual expressions represented parts of an inner spiritual dialogue that was beyond that of social learning. They also noted that parents were shocked by their child's spiritual dialogue and awareness. Moreover, previous scholarship (Hay and Nye 2006; Woolley et al. 2008; Hooffman 1992; Karleson et al. 2013) further confirmed a lack of openness regarding children's spiritual dialogue with other people. These findings are consistent with Boynton's (2016) research where children did not share their spiritual thoughts and experiences with others, and that they appeared to articulate spiritual matters at a very high level. It is evident that children have surprised adults regarding the level of their spiritual capacities, experiences, and understandings, and this is a very important consideration if we are to mitigate situations of suppressed spirituality.

Corresponding with Vialle et al. (2008), Boynton (2016) noted that there was complexity and abstraction in children's dialogue, which was beyond the accepted constructions of child development stage theorists. Vialle et al. (2008) found that although older preadolescent children were able to provide more details and facts about their views on the world and existence, there were no major differences in the content of the conversations they held with children, even as young as five years of age.

Attunement to the spiritual worldview of children involves spiritual awareness and listening, while considering the relational consciousness and spiritual capacities of the child. It is imperative to listen to the child's metaphysical concerns and meanings of events. Creating space for mutual spiritual understanding shifts practitioners from just gathering and assessing spiritual information to attunement and validation of the child's spiritual experiences. It employs an anti-oppressive, multidimensional, and collaborative clinical process of exploring spiritual worldviews and meaning systems through the creation of shared understandings.

\section{Opening One's Heart for Sacred Relationships}

The children Boynton (2016) interviewed offered important advice for counselling practice. They wanted counsellors to open their hearts to allow spirituality to be present and validated, and for clinicians to know that kids have deep spiritual thoughts and questions and require support and protection. Three of the children envisioned that listening and talking about spirituality in counselling could be fascinating and a fun experience. They also felt that establishing trust with clients was paramount, and that clinicians should allow 
the child to share and express their spirituality at their own pace. Children considered that spiritual dialogue is a two-way process and that there is a level of co-creation involved. This confirms the critical importance of the aspects of relationality and connectedness and the need for empathy and a heart connection for spirituality to have sacred space within the counselling relationship. The manner of connection and attuning to the other happens at multiple levels and often is intuitive in nature and beyond the expression of words.

Martin Buber ([1937] 1958) first presented a relational dynamic of how we engage with one another, the world, and a higher power. Buber ([1937] 1958) described an "I-thou" relationship as a perception of another as a whole being, where mutuality, connectedness, and reciprocity are involved. Hart (2003) discussed that there is a "knowingness" in the heart that opens the individual to deeper relationships, compassion, and empathy. Rogers (1980) transformed the counselling space in talking about empathy, genuineness, and unconditional positive regard. This entails entering a full state of "being with", open and sensitive to felt meanings flowing within and from another individual. Cochran and Cochran (2021) stressed engaging in deep connection and deep empathy, which involves "experiencing the inner world of another, the other person's full and unique experience" (p. 58), which is a shared experience beyond active listening. This deep sensing and attunement coupled with the I-thou relationship is what creates the magic and power of a deeper authentic heart-based and soul-based connection. It allows for a safe space for bearing witness to pain, struggle, and strife, while offering safety, care, and empathy. It also is facilitative of new experiences for the client to experience emotions deeply, interpret thoughts, feelings, beliefs, and values, to make meaning of TGL and suffering, while developing a new awareness, and a revised sense of identity. For some children experiencing TGL, their ability to readily know when the "other" is not authentically present or congruent in their thoughts and actions, or mind and heart, is heightened. This means that counsellors must be fully present in opening their hearts to spirituality.

\section{Recognizing the Role of Spirituality in TGL Meaning Creation and Identity}

Counsellors working with children must understand the complexity and depth of concerns for children experiencing TGL, which include spiritual needs. TGL can overlap with interrelated responses and processes. Responses of TGL in children can vary and may include confusion and preoccupation, pining, yearning, loneliness, a range of dysphoric emotions, withdrawal, oppositional and aggressive behaviour, school problems, avoidance of feelings and expression, physical symptoms, peer and relationship issues, loss of motivation, withdrawal, isolation, and loss of interest in activities, which can persist intermittently and, for some, over long periods of time (Bonanno and Kaltman 2001; Cohen et al. 2010; Fiorini and Mullen 2006; Pearlman et al. 2010). Adult responses to children who are grieving are one of the most important influences on children's reactions and responses (Walters 2008). Without support from caring adults, these responses can elicit feelings of fear and anxiety, sadness and depression, a lack of a sense of control, or loss of a sense of identity (Cohen et al. 2010; Fiorini and Mullen 2006). The child may experience intensified negative feelings, including powerlessness, ambivalence, guilt or even anger (Attig 2004; Hooyman and Kramer 2006). Attig (2004) contends that the disenfranchisement of children's TGL experience undermines coping and coming to terms with hurt, suffering, and hardship; it deprives the individual of comfort and support, and the potential to thrive and live meaningfully. TGL and disenfranchisement can also lead to traumatic, prolonged, or complicated grief (these terms are often used interchangeably) (Cohen et al. 2006, 2010).

When children experience the death of a caregiver, sibling, or close relation, it is often deemed by the child to be traumatic, and the likelihood of the child to struggle strongly increases. Contrary to mainstream conceptions, children recognize death as permanent by the age of five, and by age eight, they begin to make meaning of the death (Hooyman and Kramer 2006). The death of someone can bring forth questions or ponderings related to life, death, the existence of an afterlife, or the purpose of death and/or suffering in life, creating a need for existential meaning making. Pearlman et al. (2010) convey that risk of 
suicide is relevant in children experiencing TGL. Children may wish to be reunited with the person who has died (Pearlman et al. 2010; Webb 2003). This desire may not necessarily mean that the child wants to die; rather, it may represent an expression of confused and sad emotions (Pearlman et al. 2010) and a strong desire for connection. A safety-first stance is imperative when working with children, while simultaneously recognizing the needs for continuing bonds and attachment concerns and any spiritual needs.

When children experience sudden or unexpected TGL events that are beyond their perspective of day-to-day familiarity, or that lack contextual fit, they are challenged with making sense of a disrupted worldview and constructing a revised worldview, and a self-identity that includes negative aspects and often nasty bits from the trauma that may be threatening and painful (Corr 2000; Gillies and Neimeyer 2006; Janoff-Bulman 2006; Mossige et al. 2005). This process can challenge a child's spiritual confidence, create a loss of ontological security (our sense of rootedness) and a crisis of meaning, and ruptures in previously supportive spiritual relationships (Boynton 2016; Angell et al. 1998; Tedeschi and Calhoun 2006). Gabarino and Bedard (1996) conveyed that TGL can involve enormous challenges to metaphysical and spiritual meanings and spirituality, which can pose great struggles for children attempting to process difficult ruminations on their own. Therefore, adult guidance in the facilitation of expressing narratives through organizing and constructing meaning of traumatic experiences is imperative. Thompson (2007) argued that spirituality can provide an avenue for meaning making.

Spiritual meaning reconstruction involves engaging the child in identifying troublesome narratives and creating new coherent frameworks of meaning, reconceptualizing relationships and roles in events, and often a revised sense of self. In spiritual meaning making, children draw upon cognitions, prior learning, family beliefs, social and cultural stories and narratives, including media and popular cultural, and spiritual frameworks (Boynton 2016; Hyde 2008). Walters (2008) contends "when a child is assisted in making grief meaningful, he or she is also afforded an opportunity to enrich their spiritual resourcefulness" (p. 277). Boynton (2016) found children engaged in processing TGL and wrestling with spiritual struggles and existential questions that caused them to deeply consider these aspects more abstractly, contrary to popular spiritual developmental theories. She further discovered that spiritual processes, behaviours, and engagement in spiritual activities and spiritual relationships were activated because of TGL. The adverse experiences "sparked and catapulted" the need for existential meaning making, deeper spiritual contemplation, and engagement in spiritual rituals and activities. In particular, children entered processes of spiritual rumination, questioning, and reflecting on the TGL event, as well as changes that the event created in their life, its related meaning, purpose, and life itself. She found that children demonstrated capacities in Fowler's (1981) synthetic conventional stage (adolescence), where they were integrating spirituality beyond the family system. Several counsellors in Boynton's (2016) study disclosed how the children asked mature existential questions, engaged in spiritual reasoning, and queried the spiritual purpose of things, and were deemed to be growing up too fast.

Although knowledge and theoretical perspectives on children's cognitive and spiritual development can be helpful in thinking about cognitive capacities such as conceptualizations of traumatic events and death, and considerations for how children may cope and respond to TGL, counsellors need to be open to discrepancies in theory and what they notice in practice. When supporting children through TGL, it is crucial for counsellors to create safe and sacred space for conversations surrounding spirituality and that include the spiritual and/or religious developmental level of the child's narrative and capacity, which may not be congruent with stage theories. A holistic perspective must include how spirituality plays a role in a child's experience after TGL. Furthermore, when we view children holistically as spiritual beings, we can empower them and assist with deeper spiritual meaning making (Dudley 2016) and healthy reconstruction of narratives and relationships while facilitating PTG. 


\section{Creating Safe Space for Spirituality}

We have discussed the first four components of the proposed spiritually sensitive framework, which create an understanding as to why holistic spiritual approaches are supportive of the child's healing process. We now shift to ways spirituality can be integrated within counselling practice to further create a safe space for children to fully engage in the healing process.

The children in Boynton's (2016) research expressed that they wanted spiritual dialogue and content to involve creativity, play, and expression. They felt it was important for clinicians to understand how the child makes sense of the world and their spiritual worldview through this creative spiritual engagement. They also conveyed that attending to spirituality in practice included figuring things out, talking about spiritual struggles to alleviate distress, and helping the child to not be afraid to talk about their spiritual life. In relation to spiritual experiences, they strongly stated that it was crucial children be believed regarding their spiritual experiences, and that these perspectives be accepted as truth for them and their reality. Counsellors who accept children as spiritual beings, create a safe space for the sacred, and attune to the spiritual dimension, can connect with children around the spiritual mysteries, wonder, and awe. They are creating opportunities for children to grow and understand themselves and their place in the universe. Spiritual conversations can be facilitated, and they can also spontaneously emerge through these creative and expressive activities, which relates to expecting the unexpected (Boynton 2016; Coholic 2010; Hyde 2008).

\section{Honouring Spiritual Emergence and the Sacred Creative Expression}

Play stimulates a child's creative expression: it is a means for making sense of the world, and a process that contributes to a child's overall development. Play, and creative and expressive therapies, are transformational pathways to the sacred, and internal and external spiritual meaning making surrounding life, existence and beyond (Bhagwan 2009; Boynton and Vis 2011). Adams et al. (2016) found that, in the literature, play was the main difference between adolescent and childhood spirituality. Play offers a mode for existential expression, particularly when there is a lack of language, and it facilitates creativity, imagination, and freedom from restrictions (Richardson 2015). Richardson (2015) expressed "In attempting to understand childhood spirituality and the meanings children gave to their experiences of illness, play became a window through which to gaze upon this often hidden part of their being" (p. 103). Expressions of spirituality can be facilitated or emerge through creativity in play, art, drama, and music, and may involve symbolic expression that enable children to explore and create meanings and can elicit the child's conceptualization of spirituality (Boynton and Vis 2011; Coholic 2010; Webb 2003).

Spiritual struggles, and feelings that are uncomfortable or difficult to talk about, are often revealed and released through creative expressive therapies (Webb 2003). Play allows the child to process and communicate feelings and reactions, and spiritual meanings and it can facilitate resolution of TGL (Edgar-Bailey and Kress 2010). Play and creative expression provide a non-threatening, safe, symbolic distance from the intensity of the emotions and indirect confrontation of traumatic events (Crenshaw 2005; Green and Connolly 2009). Gabarino and Bedard (1996) proclaimed, "the importance of play to children as they process their grief cannot be overstated" (p. 44). Thus, play and creativity are not only transformational in instances of TGL but woven into the spiritual expressions of children, which fosters and supports healthy coping and meaning making.

Mata-McMahon (2017) suggested that humour plays a role in expressing a child's spiritual self. Combined in play via storytelling, spiritual expression can be revealed in moments of humour and joy. Mountain (2016) connected play therapy with children's spirituality, and it allows children to express themselves at their own level and pace. Play often involves storytelling and reminiscence, which have adaptive therapeutic possibilities that can help us reframe traumatic events into resiliencies, strengths, and stronger coping abilities (Angell et al. 1998). Crenshaw (2005) and Corr (2000) present a diverse range of 
stories that counsellors can use as tools to stimulate children's TGL processing and teach concepts of death and recovery in a therapeutic context.

Rituals are also helpful engagement tools which allow spiritual expression and connection and can create sacred moments. Rituals allow children to reminisce and explore memories, and they provide symbolic expressions of feelings and thoughts that assist the grief process (Hooyman and Kramer 2006; Lewis and Hoy 2011). Rituals can evoke an emotional connection and support the transformation of the relationship to a spiritual connection, providing emotional comfort (Lewis and Hoy 2011). Rituals can include lighting a candle in memory of a loved one, visiting the gravesite, displaying photos, wearing or interacting with a belonging of the deceased, planting trees, writing letters or letting balloons go with messages inside (Boynton and Vis 2011; Lewis and Hoy 2011).

\section{Spiritually Symbolic Objects and Spiritual Bonds}

It is important for counsellors to integrate grief processes, acknowledgment of continuing bonds, and application of the dual process model, when working with children experiencing TGL (Worden 2009; Klass et al. 1996). Pearlman et al. (2010) emphasized that bereaved children should continue and preserve bonds with loved ones. Redefining and maintaining a connection can become essential for meaning reconstruction of a spiritual worldview and a renewed sense of self (Pearlman et al. 2010). Moreover, strategies formulated from the child's spiritual expressions and practices can further support worldview reconstruction.

One such example in the continuing bond process is that the relationship with the deceased becomes transformed from a physical one to an emotional and spiritual relationship (Rothaupt and Becker 2007). In this process, an individual may remain physically attached to objects that belonged to or represent the loved one, and these objects have been coined as linking objects (Andrews and Marotta 2005; Rothaupt and Becker 2007). However, Boynton (2016) has termed these linking objects as "spiritually symbolic objects" as children described the objects as holding spiritual meaning and engaging with the objects had a transcendent quality creating spiritual relationships and bonds to place, time, and people. Spiritually symbolic objects can also be used in rituals, facilitate mindfulness, and aid in moments of flow and transcendence. For instance, objects from nature can transport an individual's thoughts and feelings to another place and time by assisting in connecting to the spiritual realm and/or ground a person to the present moment. Some objects, such as worry stones, crystals, dream catchers, and incense, are viewed as having the ability to absorb and combat or dissipate negative emotions and anxious feelings from the child and are used when the child is experiencing distress (Boynton 2016; Fletcher and Ota 1997).

\section{Facilitating Spiritual Coping and Growth}

Counsellors often assist children in developing or strengthening coping. Incorporating meditation, guided imagery, and breathing techniques can assist children with relaxation and coping and can be spiritual in nature. Positive and spiritual methods of coping can contribute to a sense of control, mastery and hope, which are necessary in recovery from TGL (Nader 2008; Thompson and Walsh 2010). Children articulate that prayer is a common spiritual activity and feel that praying to a higher power helps them through adversity and loss, makes them feel good or happy, and assists in achieving goals (Boynton 2016; Moore et al. 2012). Children shared with Boynton (2016) that when they go through difficult times, they communicate their needs to a higher power, a spiritual entity, or natural beings such as trees or animals for assistance. They disclosed how they shared deep personal struggles, thoughts, and feelings with these spiritual entities. Spiritual relationships, prayer, and the use of spiritually symbolic objects were the most salient supportive and helpful spiritual coping activities children appeared to engage in during adversity. They also used distraction techniques and relied on time to improve a situation. In facilitating spiritual coping and growth, counsellors can include other spiritual coping practices such as mindfulness, nature therapy, yoga, breathwork, spiritual readings, and 
the use of angel cards if these were amenable to the child and family. Supporting children's spiritual connectedness, meaning and coping would likely increase the potential for PTG.

\section{Expect the Unexpected}

Children are explorers and adventurers in their world. They ask existential questions and are unabashed from asking about or pointing towards differences. Early educators, Nimmo et al. (2019), highlighted how spiritual inclusivity in safe spaces honours the child's authentic self that includes their religious traditions and/or spiritual practices. A spiritually sensitive framework requires a suspension of disbelief on behalf of the counsellor to be ready and flexible in welcoming the unexpected gifts the spiritual child may bring to the session. Boynton (2016) noted children engaged in what were deemed to be weird conversations related to existence and possibilities. Counsellors may need to suspend judgement and theoretical knowledge in order to fully embrace what emerges in the co-creative process related to the spiritual dimension, especially in the assessment and treatment of TGL.

\section{Implications for Future Practice and Research}

Kvarfordt and Sheridan (2007) interviewed social workers in the United States, discovering that many incorporated a variety of spiritually based interventions with youth. The social workers believed that spirituality was significant for the youth they encountered. However, they failed to receive adequate or any education or training on how to integrate spiritually based interventions. In a later study, Kvarfordt and Herba (2018) conducted a survey of 307 social workers and social service workers working with youth in Ontario, Canada. They also reported similar results where practitioners felt spirituality was relevant for working with children and they were using various spiritual approaches in interventions. Yet, still a decade later, $69 \%$ of social workers indicated either no or very little content related to spirituality in their education and training. The main barriers to integrating spiritually sensitive practice with children were a lack of knowledge and experience and a lack of agency and supervisory support. They argued for spiritually sensitive practice content, spiritual development, and intervention approaches to be included in academia and training. Moore et al. (2012) declared that further research into spirituality and its relationship to children's coping through TGL was warranted. They also asserted that understanding the role of spirituality in coping and wellbeing was important for educational and clinical settings. The clinicians in Boynton's (2016) study also shared similar concerns and needs.

Lastly, opening space for spiritually sensitive frameworks requires more research from the child's perspective in order to attend to their unique spiritual expressions, activities, and practices. How children create meaning is multidimensional and requires further study regarding their spirituality and/or religiosity. More research situated from the child's perspective will help to further support children's ways of knowing and ability to express themselves, particularly when those expressions are situated in the dimension of spirituality. Research that includes observing counselling sessions could illuminate tacit features of spirituality, implicit and explicit spiritual dialogue, and implicit and explicit spiritual interventions, as well as the qualities of the spiritual relationship between clients and clinicians. Development and research on spiritual interventions and practice are required, along with counsellor training.

\section{Conclusions}

This article has presented a spiritually sensitive framework to help social work practitioners and counsellors understand the importance of the spiritual dimension and how to integrate this understanding into practice. It encompasses eight areas pertinent for working with children experiencing TGL, including conceptualizing spirituality, accepting children as spiritual beings, opening one's heart to sacred relationships, recognizing the importance of spirituality following TGL, creating safe spaces for spirituality to emerge, 
honouring spiritual emergence and sacred creative expression, facilitating spiritual coping and growth, and expecting the unexpected. Ultimately, opening up to the sacredness of children's spirituality is critical for a spiritually sensitive holistic approach in counselling.

Children within Boynton's (2016) study wanted practitioners and family members to allow them to fully express their spirituality through TGL. Part of this expression includes the sacred, the fantastical, and the deep relational connections they have with others, nature, and/or a higher power. It requires attunement to the child's understanding of spirituality for processing and integrating the child's TGL events in spiritual meaning making. Facilitating spiritual healing is integral to PTG, and as counsellors open safe spaces in supporting a child's expression of their authentic and spiritual self, this will ultimately foster a deeper respect for the client.

Author Contributions: H.M.B. 65\% Conceptualization, Formal Analysis, Investigation, Methodology, Writing, Review, Editing, supervision. C.M. 35\% Writing, Review, Editing. Both authors have read and agreed to the published version of the manuscript.

Funding: The researcher received funding from the Social Sciences and Humanities Research Council of Canada for her PhD program.

Institutional Review Board Statement: The study was conducted according to the guidelines of the Declaration of Helsinki, and approved by the Conjoint Faculties Research Ethics Board of the University of Calgary (7220 5 March 2012).

Informed Consent Statement: Informed consent was obtained from all subjects involved in the study.

Data Availability Statement: Data is confidentially stored by the researcher as outlined in the Ethics approval process.

Conflicts of Interest: There are no conflict of interest.

\section{References}

Adams, Kate, Rebecca Bull, and Mary-Louise Maynes. 2016. Early Childhood Spirituality in Education: Towards an Understanding of the Distinctive Features of Young Children's Spirituality. European Early Childhood Education Research Journal 24: 760-74. [CrossRef]

Andrews, Catherine R., and Sylvia A. Marotta. 2005. Spirituality and Coping Among Grieving Children: A Preliminary Study. Counselling and Values 50: 38-50. [CrossRef]

Angell, Brent G., Brent C. Dennis, and Lisa E. Dumain. 1998. Spirituality, Resilience and Narrative: Coping with Parental Death. Families in Society 79: 615-30. [CrossRef]

Attig, Thomas. 2004. Disenfranchised Grief Revisited: Discounting Hope and Love. Omega 49: 197-215. Available online: https: / / sites.ualberta.ca/ \{\}jennyy / PDFs / 14022506.pdf (accessed on 7 July 2021). [CrossRef]

Bhagwan, Raisuyah. 2009. Creating Sacred Experiences for Children as Pathways to Healing Growth and Transformation. International Journal of Children's Spirituality 14: 225-34. [CrossRef]

Bonanno, George A., and Stacey Kaltman. 2001. The Varieties of Grief Experience. Clinical Psychology Review 21: 705-35. [CrossRef]

Bosacki, Sandra, and Cathy Ota. 2000. Preadolescents' voices: A Consideration of British and Canadian Children's Reflections on Religion, Spirituality, and Their Sense of Self. International Journal of Children's Spirituality 5: 203-19. [CrossRef]

Boynton, Heather M. 2016. Navigating in Seclusion: The Complicated Terrain of Children's Spirituality in Trauma, Grief, and Loss. Ph.D. thesis, University of Calgary, Calgary, AB, Canada. Available online: https:/ / prism.ucalgary.ca/bitstream/handle/11023/ 2997/ucalgary_2016_boynton_heather.pdf;jsessionid=8E3335341E52DC438329F229A7BDF1A9?sequence=4 (accessed on 7 July 2021).

Boynton, Heather M. 2021. "It's Weird and Taboo: The Isolating Experience of Children's Spirituality". Unpublished manuscript. June. Boynton, Heather M., and Jo-Ann Vis. 2011. Meaning Making, Spirituality, and Creative Expressive Therapies: Pathways to Posttraumatic Growth in Grief and Loss for Children. Counselling and Spirituality 30: 137-59. [CrossRef]

Buber, Martin. 1958. I and Thou. Translated by R. G. Smith. New York: Charles Scribner's and Sons. First published 1937.

Burkhardt, Margaret A. 1991. Spirituality and Children: Nursing Considerations. Journal of Holistic Nursing 9: 31-40. [CrossRef]

Burkhardt, Margaret A., and Mary Gail Nagai-Jacobson. 2002. Spirituality: Living our Connectedness. Albany: Delmar Cengage Learning.

Canda, Ed, and Leona Furman. 2010. Spiritual Diversity in Social Work Practice: The Heart of Helping, 2nd ed. New York: The Free Press.

Canda, Ed, Leona Furman, and Hwi-Ja Canda. 2020. Spiritual Diversity in Social Work Practice: The Heart of Helping, 3rd ed. New York: Oxford University Press.

Carroll, Maria. 1998. Social Work's Conceptualization of Spirituality. Social Thought 18: 1-13. [CrossRef] 
Champagne, Elaine. 2001. Listening to ... Listening for ... : A Theological Reflection on Spirituality in Early Childhood. In Spiritual Education. Cultural, Religious and Social Differences: New Perspectives for the 21st Century. Edited by Jane Erricker, Cathy Ota and Clive Erricker. Brighton: Sussex Academic Press, pp. 76-87.

Cochran, Jeff, and Nancy Cochran. 2021. The Heart of Counseling: Practical Counseling Skills Through Therapeutic Relationships. New York: Routledge.

Cohen, Judith A., Anthony Mannarino, and Esther Deblinger. 2006. Treating Trauma and Traumatic Grief in Children and Adolescents. New York: The Guildford Press.

Cohen, Judith A., Lucy Berliner, and Anthony Mannarino. 2010. Trauma Focused CBT for Children with Co-occurring Trauma and Behaviour Problems. Child Abuse E Neglect 34: 215-24. [CrossRef]

Coholic, Diana. 2010. Arts Activities for Children and Young People in Need: Helping Children to Develop Mindfulness, Spiritual Awareness and Self-Esteem. London: Jessica Kingsley Publishers.

Coles, Robert. 1990. The Spiritual Life of Children. Boston: Houghton Mifflin.

Corr, Charles A. 2000. What do we Know About Grieving Children and Adolescents? In Living with Grief: Children, Adolescents and Loss. Edited by Kenneth J. Doka. Washington, DC: Hospice Foundation of America, pp. 21-32.

Crenshaw, David. 2005. Clinical Tools to Facilitate Treatment of Childhood Traumatic Grief. Omega 51: 239-55. [CrossRef]

Csikszntmihalyi, Mihaly. 2008. Flow: The Psychology of Optimal Experience. New York: Harper Perennial.

De Souza, Marian. 2012. Connectedness and Connectedness: The Dark Side of Spirituality-Implications for Education. International Journal of Children's Spirituality 17: 291-303. [CrossRef]

Dudley, James. 2016. Spirituality Matters in Social Work: Connecting Spirituality, Religion and Practice. New York: Routledge.

Edgar-Bailey, Meredith, and Victoria E. Kress. 2010. Resolving Child and Adolescent Traumatic Grief: Creative Techniques and Interventions. Journal of Creativity in Mental Health 5: 158-76. [CrossRef]

Fiorini, Jody J., and Jodi A. Mullen. 2006. Counselling Children and Adolescents Through Grief and Loss. Champagne: Research Press.

Fisher, John W. 2009. Getting the Balance: Assessing Spirituality and Well-Being Among Children and Youth. International Journal of Children's Spirituality 14: 273-88. [CrossRef]

Fletcher, Mandy, and Cathy Ota. 1997. Religious Identity and Children's Worldviews. In The Education of the Whole Child. Edited by Clive Erricker, Jane Erricker, Danny Sullivan, Cathy Ota and Mandy Fletcher. London: Cassell, pp. 114-31.

Fowler, James. 1981. Stages of Faith. New York: Harper Collins.

Gabarino, James, and Claire Bedard. 1996. Spiritual Challenges to Children Facing Violent Trauma. Childhood 3: 467-78. [CrossRef]

Gillies, James, and Robert A. Neimeyer. 2006. Loss, Grief and the Search for Significance: Toward a Model of Meaning Reconstruction in Bereavement. Journal of Constructivist Psychology 19: 31-65. [CrossRef]

Green, Eric J., and Marianne E. Connolly. 2009. Jungian Family Sandplay with Bereaved Children: Implications for Play Therapists. International Journal of Play Therapy 18: 84-98. [CrossRef]

Hart, Tobin. 2003. The Secret Spiritual World of Children: The Breakthrough Discovery that Profoundly Alters our Conventional View of Children's Mystical Experiences. Novata: New World Library.

Hawkins, Catherine A. 2005. Spiritually Sensitive Practice with Children, Youth and Families. In Child Welfare for the Twenty-First Century: A Handbook of Practices, Policies, and Programs. Edited by Gerald P. Mallon and Peg McCartt Hess. New York: Columbia University Press, pp. 146-261.

Hay, David, and Rebecca Nye. 1998. The Spiritual Child. London: Harper Collins.

Hay, David, and Rebecca Nye. 2006. The Spiritual Child, 2nd ed. London: Harper Collins.

Hooffman, Edward. 1992. Vision of Innocence: Spiritual and Inspirational Experience of Childhood. Boston: Shambhalla.

Hooyman, Nancy R., and Betty J. Kramer. 2006. Living Through Loss: Interventions Across the Life Span. New York: Columbia University Press.

Hyde, Brendan. 2008. Children and Spirituality: Searching for Meaning and Connectedness. London: Jessica Kingsley.

Janoff-Bulman, Ronnie. 2006. Schema-Change Perspectives on Posttraumatic Growth. In Handbook of Posttraumatic Growth: Research and Practice. Edited by Lawrence G. Calhoun and Richard G. Tedeschi. Mahwah: Lawrence Earlbaum Associates, pp. 81-99.

Karleson, May Lene, Adrian Cole, and Emma Williams. 2013. They Never Listen: Towards a Grounded Theory of the Role Played by Trusted Adults in the Spiritual Lives of Children. Mental Health, Religion \& Culture 17: 297-312.

Klass, Dennis, Phyllis R. Silverman, and Steven Nickman, eds. 1996. Continuing Bonds: New Understandings of Grief. Washington, DC: Taylor \& Francis.

Koenig, Harold. 2011. Spirituality and Health Research: Methods, Measurements, Statistics, and Resources. West Conshohocken: Templeton Press.

Kvarfordt, Connie L., and Kasha Herba. 2018. Religion and Spirituality in Social Work Practice with Children and Adolescents: A Survey of Canadian Practitioners. Child \& Adolescent Social Work Journal 35: 153-67. [CrossRef]

Kvarfordt, Connie L., and Michael J. Sheridan. 2007. The Role of Religion and Spirituality in Working with Children and Adolescents: Results of a National Survey. Journal of Religion and Spirituality in Social Work 26: 1-23. [CrossRef]

Lewis, Laura, and W. G. Hoy. 2011. Bereavement Rituals and the Creation of Legacy. In Grief and Bereavement in Contemporary Society. Edited by Robert A. Neimeyer, Darcy L. Harris, Howard R. Winokuer and Gordon F. Thornton. New York: Routledge, pp. 315-24.

Lovelock, Pauline, and Kate Adams. 2017. From Darkness to Light: Children Speak of Divine Encounter. International Journal of Children's Spirituality 22: 36-48. [CrossRef] 
MacDonald, Douglas A. 2000. Spirituality: Description, Measurement, and Relation to the Five Factor Model of Personality. Journal of Personality 68: 153-97. [CrossRef] [PubMed]

Mata-McMahon, Jennifer. 2017. Spirituality and Humour: Making Connections for Early Childhood Education. International Journal of Children's Spirituality 22: 170-78. [CrossRef]

McLaughlin, Terrence. 1996. Education of the Whole Child? In Education, Spirituality, and the Whole Child. Edited by Ron Best. London: Cassell.

Miller, John. 2007. Whole Child Education. Toronto: University of Toronto Press.

Moore, Kelsey, Victoria Talwar, and Sandra Bosacki. 2012. Children's Perceptions of Spirituality: Diverse Voices. International Journal of Children's Spirituality 17: 217-34. [CrossRef]

Mossige, Svein, Tine K. Jensen, Wenke Gulbrandsen, Sissel Reichelt, and Odd Arne Tjersland. 2005. Children's Narratives of Sexual Abuse: What Characterizes them and how do they Contribute to Meaning-Making? Narrative Inquiry 15: 377-404. [CrossRef]

Mountain, Vivienne. 2016. Play Therapy: Respecting the Spirit of the Child. International Journal of Children's Spirituality 21: 191-200. [CrossRef]

Nader, Kathleen. 2008. Understanding and Assessing Trauma in Children and Adolescents: Measures, Methods, and Youth in Context. New York: Routledge.

Nimmo, John, Mona Abo-Zena, and Debbie LeeKeenan. 2019. Finding a Place for the Religious and Spiritual Lives of Young Children and Their Families. YC: Young Children 74: 37-45.

Pearlman, Michelle Y., Karen D'Angelo Schwalbe, and Marylène Cloitre. 2010. Grief in Childhood: Fundamentals of Treatment in Clinical Practice. Washington, DC: American Psychological Association.

Ratcliff, Donald. 2008. “The Spirit of Children Past:" A Century of Children's Spirituality Research. In Nurturing Children's Spirituality: Christian Perspectives and Best Practices. Edited by Holly C. Allen. Eugene: Cascade Books, pp. 21-42.

Reimer, Kevin S., and James L. Furrow. 2001. A Qualitative Exploration of Relational Consciousness in Christian Children. International Journal of Children's Spirituality 6: 7-22. [CrossRef]

Richardson, Holly R. L. 2015. More Than Just Child's Play: Symbolic Expressions of Illness and Spirit. International Journal of Children's Spirituality 20: 100-13. [CrossRef]

Roehlkepartain, Eugene C., Pamela E. King, Linda M. Wagener, and Peter L. Benson. 2006. The Handbook of Spiritual Development in Childhood and Adolescence. Thousand Oaks: Sage.

Rogers, Carol. 1980. A Way of Being. Boston: Houghton Mifflin.

Rothaupt, Jeanne W., and Kent Becker. 2007. A Literature Review of Western Bereavement Theory: From Decathecting to Continuing Bonds. The Family Journal: Counseling and Therapy for Couples and Families 15: 6-15. [CrossRef]

Sheridan, Michael J. 2004. Predicting the Use of Spiritually-Derived Interventions in Social Work Practice: A Survey of Practitioners. Journal of Religion and Spirituality in Social Work 23: 5-25. [CrossRef]

Sveidqvist, Veronika, Natacha Joubert, Julie Greene, and Ian Manion. 2003. Who am I, and Why am I Here? Young People's Perspectives on the Role of Spirituality in the Promotion of their Mental Health. International Journal of Mental Health Promotion 5: 36-44. [CrossRef]

Swinton, John. 2001. Spirituality and Mental Health Care: Rediscovering a 'Forgotten' Dimension. Philadelphia: Jessica Kingsley.

Tedeschi, Richard G., and Lawrence G. Calhoun. 2006. Time of Change? The Spiritual Challenges of Bereavement and Loss. Omega 53: 105-16. [CrossRef]

Thompson, Neil, and Mary Walsh. 2010. The Existential Basis of Trauma. Journal of Social Work Practice 24: 377-89. [CrossRef]

Thompson, Neil. 2007. Loss and Grief: Spiritual Aspects. In Spirituality, Values and Mental Health: Jewels for the Journey. Edited by Mary Ellen Coyte, Peter Gilbert and Vicky Nicholls. Philadelphia: Jessica Kingsley, pp. 70-79.

Vialle, W., Russel Walton, and Stuart Woodcock. 2008. Children's Spirituality: An Essential Element in Thinking and Learning in New Times. Research Online. pp. 143-60. Available online: http:/ / ro.uow.edu.au/cgi/viewcontent.cgi?article=1042\&context= edupapers (accessed on 7 July 2021).

Walters, David A. 2008. Grief and Loss: Towards an Existential Phenomenology of Child Spirituality. International Journal of Children's Spirituality 13: 277-86. [CrossRef]

Webb, Nancy Boyd. 2003. Play and Expressive Therapies to Help Bereaved Children: Individual, Family and Group Treatment. Studies in Social Work 73: 405-22. [CrossRef]

Wilkinson, Courtney. 2012. Spirituality and Religion in Social Work: Respondent Definitions. St. Catherine University. Master of Social Work Clinical Research Papers. Available online: http:/ / sophia.stkate.edu/cgi/viewcontent.cgi?article=1103\&context=msw_papers (accessed on 28 January 2015).

Woolley, Richard, Brendan Hyde, and Kate Adams. 2008. The Spiritual Dimension of Childhood. London: Jessica Kingsley.

Worden, J. William. 2009. Grief Counseling and Grief Therapy: A Handbook for the Mental Health Practitioner, 4th ed. New York: Springer Publishing Company. 